\title{
The Apoptosome: Emerging Insights and New Potential Targets for Drug Design
}

\author{
Marcello D'Amelio, ${ }^{1,2}$ Elisa Tino, ${ }^{1,2}$ and Francesco Cecconi ${ }^{1,2,3}$
}

Received April 13, 2007; accepted June 26, 2007; published online August 3, 2007

\begin{abstract}
Apoptosis plays a crucial role in tissue homeostasis, development and many diseases. The relevance of Apaf1, the molecular core of apoptosome, has been underlined in mitochondria-dependent apoptosis, which according to a growing body of evidence, is involved in various pathologies where the equilibrium of life-and-death is dysregulated, such as heart attack, stroke, liver failure, cancer and autoimmune diseases. Consequently, great interest has emerged in devising therapeutic strategies for regulating the key molecules involved in the life-and-death decision. Here we review recent progress in apoptosis-based pharmacological therapies and, in particular, we point out a possible role of the apoptosome as an emerging and promising pharmacological target.
\end{abstract}

KEY WORDS: apoptosis and disease; apoptosis induction; apoptosis inhibition; apoptosome regulation.

\section{INTRODUCTION}

Apoptosis is an evolutionarily conserved form of cell death which regulates development and tissue homeostasis and also plays a pivotal role in the cytotoxic activity of most chemotherapeutic drugs and in the response to pathogens. Apoptosis is characterized by morphological changes of the cell such as chromatin condensation, membrane blebbing, cell shrinkage and finally cellular fragmentation in vesicular bodies subsequently taken up by macrophages (1).

In humans about a hundred thousand cells are produced every second by mitosis and a similar number of cells die by apoptosis; this physiological process is essential for the maintenance of tissue homeostasis and serves to remove extraneous or dangerous cells.

An inappropriately low rate of apoptosis can promote the survival and accumulation of abnormal cells which can contribute to cancer development or autoimmune disease. Conversely, many acute pathologies such as heart attack, stroke and liver failure are associated with abrupt cell death of whole tissue areas (myocardium, central nervous system, liver), whereas many neurodegenerative diseases are the result of a more slowly progressive neuronal death.

It is evident that apoptotic defects and/or aberrations in apoptotic responses to death signals can contribute to various human diseases where there is an excessive or deficient cell death.

The current review, besides providing an overview of the apoptotic machinery and the apoptosome structure, will focus

Marcello D'Amelio and Elisa Tino equally contributed to this work.

${ }^{1}$ Laboratory of Molecular Neuroembryology, IRCCS Fondazione Santa Lucia, 00143 Rome, Italy.

${ }^{2}$ Dulbecco Telethon Institute at the Department of Biology, University of Rome 'Tor Vergata', 00133 Rome, Italy.

${ }^{3}$ To whom correspondence should be addressed. (e-mail: francesco. cecconi@uniroma2.it) on the recent progress of apoptosis-based therapies, particular attention being paid to new and promising therapeutical tools which can modulate the apoptosome function.

\section{THE APOPTOTIC MACHINERY}

As outlined above, apoptosis is a cellular process which leads to cytoskeletal and nuclear proteolytic digestion. These typical features are the consequence of activation of a family of proteases called caspases, which are produced as zymogenes. Based on the activation order in cell death pathways, caspases are divided into two major groups: executioner caspases and initiator caspases (2). The executioner caspases, caspase-3, -6 and -7 in mammals, cleave selected substrates to produce the typical alteration changes associated with apoptosis. The executioner caspases are activated by initiator caspases, including caspase-8, -9 and -10 . By examining the patterns of caspase activation following different apoptotic stimuli, two main pathways have emerged: the death receptor pathway (extrinsic pathway) and the mitochondrial pathway (intrinsic pathway; 3,4) (Fig. 1).

The extrinsic apoptotic program, which often does not require mitochondria, is activated by death receptor stimulation. All death receptors are characterized by an intracellular motif called the death domain (DD). Upon stimulation, the death receptors interact via their DD with the DD of adaptor proteins such as Fas-Associated Death Domain (FADD). The adaptor proteins also contain a second interaction motif, the death effector domain (DED), which facilitates their binding to the initiator caspase-8 (or caspase-10) to form the death-inducing signalling complex (DISC). DISC formation activates caspase-8 (or caspase-10) (5) which subsequently cleaves and activates caspase-3. In some cell types the procaspase- 3 cleavage by DISC formation is associated to mitochondrial mediated cell death. In this case the mito- 


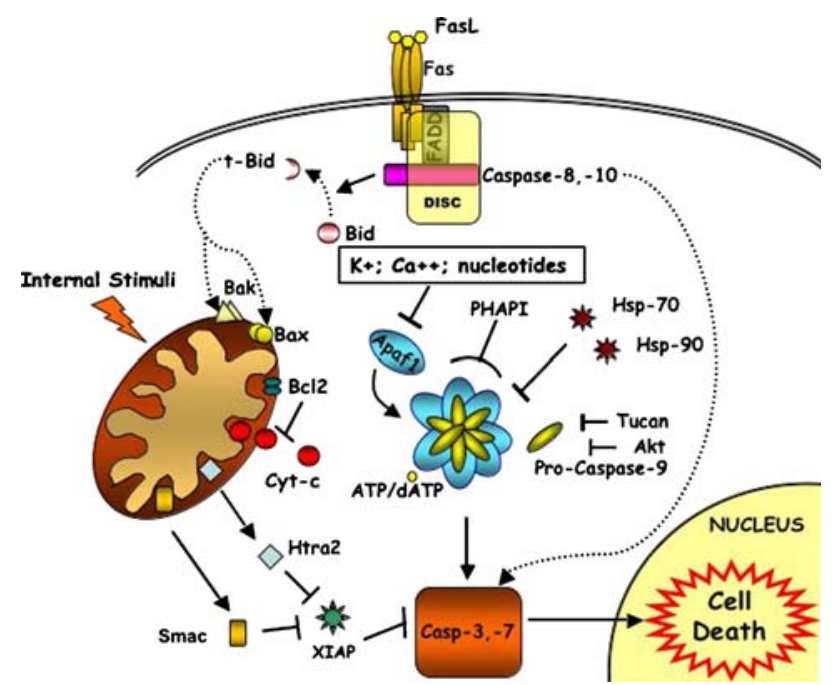

Fig. 1. Apoptosis signalling pathways. Two important pathways of caspase activation exist in mammalian cells, one involving death receptor and the other involving mitochondria (see also text); $(\rightarrow$ activation; $\dashv$ inhibition). The extrinsic cell death pathway (dotted line) is mediated by death receptors (the best studied death receptor is Fas). The binding of Fas ligand (FasL) leads to receptor activation. The Fas receptor contains a death domain $(D D)$ in its cytoplasmic region which interacts with the adaptor protein $(F A D D)$, forming the DISC (Death-Inducing Signalling Complex). DISC formation results in the activation of caspase- $8,-10$ which in turn will activate downstream effector caspase (caspase-3,-7). In the mitochondrial pathway (continuous line), which is initiated by multiple forms of cellular stress, Bax and Bak are activated at mitochondria. Also, Bid (activated by caspase- 8 cleaveage in extrinsic cell death pathway) activates Bax and Bak to mediate the release of cytochrome $c$ in the cytosol. Cytochrome $c$ and dATP trigger the assembly of the Apaf1apoptosome, which recruits and activates caspase-9. This, in turn, cleaves and activates caspase-3. The activation of caspase-3, -7 is antagonized by IAPs, which in turn can be inhibited by Smac/ DIABLO and Omi/HtrA2.

chondrial pathway is engaged through caspase-8-mediated cleavage of Bid, a pro-apoptotic member of the Bcl-2 family. Once cleaved, truncated Bid (t-Bid) translocates to the mitochondria where it induces the cytochrome $c$ release, the first step of the intrinsic pathway.

Many death signals originating from cellular stress activate an intrinsic apoptotic program which is mediated by the mitochondria. The mitochondria outer membrane permeabilization (MOMP) is an important step in the intrinsic pathway. Permeabilization mechanisms are controversial, the two principal hypotheses involving the MTP (Membrane Transition Permeabilization) and the Bcl-2 family proteins (6). The involvement of the MTP in apoptosis is debatable, as it seems more specific for necrosis (7). Thus the major role in membrane permeabilization seems to be carried out by Bcl-2 family members, even if their mechanism of action is far from clear. These proteins are characterized by the presence of one or more $\mathrm{Bcl}-2$ homology $(\mathrm{BH})$ domains. They are divided into: pro- (Bax, Bak, etc) and anti-apoptotic $\left(\mathrm{Bcl}-2, \mathrm{Bcl}-\mathrm{X}_{\mathrm{L}}\right.$, etc) proteins. Pro-apoptotic members are further divided into two subgroups: the $\mathrm{BH}$ only proteins and the proteins which possess $\mathrm{BH} 1, \mathrm{BH} 2$ and BH3 domains (8). Bax and Bak, as a consequence of apoptotic stimuli, are subject to conformational changes and oligomerization (9) and they cause membrane permeabilization by destabilizing the lipid bilayer, creating pores or interacting with channels (10). Bax and Bak are counteracted by $\mathrm{Bcl}-2$ anti-apoptotic members, which are present in the outer membrane. In this regulation the $\mathrm{BH} 3$-only proteins have an important role (11). Several models of Bcl-2 proteins' function and regulation have been proposed and they are mentioned later on when describing the $\mathrm{BH} 3$ mimetics.

The result of permeabilization is the release, into the cytoplasm, of cytochrome $c$, which, in the presence of dATP, induces the formation of the Apaf1-containing macromolecular complex called the apoptosome. This complex, in turn, binds and activates procaspase-9. Mature caspase- 9 remains bound to the apoptosome, recruiting and activating executioner caspase- 3 and/or caspase- 7 .

The absence of the apoptosome inhibits the completion of the apoptotic process in many systems. Under these conditions cells which had been induced to death cannot complete the apoptotic program even though they show some early biochemical modifications typical of programmed cell death which might affect cell survival such as the release of the cytochrome $c$ from mitochondria. Are these modifications irreversible or can cells with apoptosome impairment triggered to apoptosis be metabolically active and so have the capacity to recover? What is the point-of-no-return in apoptosis? This is a frequently addressed question not yet clarified.

The release of the cytochrome $c$ has often been considered the point-of-no-return in cell death since cytochrome $c$ is part of the mitochondrial respiratory chain which transports electrons from complex III to complex IV and is responsible for the generation of the mitochondrial membrane potential $(\Delta \Psi \mathrm{m}) . \Delta \Psi \mathrm{m}$ is needed for various functions including the production of ATP via oxidative phosphorylation. Permeabilization of the mitochondrial outer membrane and release of cytochrome $c$ should therefore, in principle, have a strong impact on mitochondrial function and behaviour because the proton gradient generated by the electron transport chain should be impaired.

However, this point is still controversial. Some reports show that release of cytochrome $c$ and disruption of $\Delta \Psi \mathrm{m}$ will kill the cell in a caspase-independent way if downstream apoptotic effects are blocked. In fact, in cells lacking caspase9 or Apaf1 death is delayed but still inevitable and such cells are, in effect, considered "zombies," i.e. severely impaired cells which cannot be defined as living normal cells (12). By contrast, other studies find that cytochrome $c$ released and diffused in the cytoplasm is able to maintain $\Delta \Psi \mathrm{m}$ and ATP generation in caspase-inhibited cells and in Apaf1 $1^{-/-}$cells. This suggests that mitochondrial recovery and cell survival are possible after the release of cytochrome $c$ which is not the point of-no-return $(13,14)$.

More recently, the Doug R. Green laboratory demonstrated that in other cell systems, such as the widely used HeLa cells, this may also be the case. They have identified glyceraldehyde-3-phosphate dehydrogenase (GAPDH) as a critical regulator of caspase-independent cell death which may follow caspase inhibition. In particular, they have shown that GAPDH-expressing cells preserved their clonogenic potential following loss of mitochondrial membrane potential, provided that caspase activation was blocked. This might 
also open up new scenarios in the field of pharmacological modulation of apoptosome functions (15).

\section{APOPTOSOME FORMATION AND STRUCTURE}

Apaf1 is characterized by three domains: the N-terminal CARD (Caspase-Recruitment Domain), the central NBD (Nucleotide Binding Domain) and the C-terminal WD-40 repeats. The CARD interacts with the CARD domain of caspase-9; the NBD binds alternatively dATP/ATP. CARD domain and NBD domain are involved in oligomerization of Apaf1 in presence of cytochrome $c$ and dATP. The Cterminal is involved in cytochrome $c$ binding. It remains unknown if other molecules can interact with this region. Apaf1 exists as a monomer in an inactive conformation, where the CARD interacts with the C-terminal so impeding the binding of procaspase-9. Cytochrome $c$, released from mitochondria, binds to WD-40 repeats thus inducing hydrolysis of dATP to dADP and the exchange of dADP with cytosolic dATP (16). When dATP binds to Apaf1 it causes a conformational change which allows the binding of procaspase-9. After activation, caspase-9 remains associated to the apoptosome (17).

The modalities of caspase- 9 activation are still unclear, although some hypotheses, recently reviewed by Bao and Shi (18), have been formulated to explain them. Briefly, according to the "induced proximity" model, caspase-9 monomers are able to activate themselves, when they are near each other (19). This model, based on experiments on caspase8 (20) and then extended to the other initiator caspases (19), does not reveal the mechanical aspects of the activation and it has been reinterpreted in two other models (21).

According to the "proximity driven dimerization" model, apoptosome recruits procaspase- 9 monomers, promoting dimerization and hence activation. This is based on the observation that procaspases are inactive as monomers, whereas dimers are active (22). A recent work (23) seems to confirm this model; in fact, a reconstituted mini-apoptosome activates caspase- 9 by a second order process compatible with the dimer-driven process. By contrast, the "induced conformation" model states that apoptosome, causing conformational changes in caspase-9, has an active role in its activation. This is based on the observation that an engineered dimeric caspase- 9 has a qualitatively different activity from the caspase-9 activated by apoptosome (24). Moreover, a recent study shows the importance of apoptosome in increasing caspase- 9 affinity for procaspase-3 (25).

Several studies based on electron cryo-microscopy have been carried out to identify the apoptosome structure. They have revealed a wheel-like complex made up of seven Apaf1 molecules $(26,27)$. According to these models, the CARD domains are located at the central hub, where the procaspase-9 interacts, whereas the WD-40 repeats form Y-shaped tails at the end of the spokes. In addition, recent studies based on computer simulation (28) and mathematical models (29) have been made to clarify the apoptosome structure and the mechanical aspects of assembly, respectively. All these efforts are important, because a deeper knowledge of the apotosome structure can be used to identify binding sites as potential targets for drug design.

\section{APOPTOSOME REGULATION}

Many factors are involved in apoptosome formation and regulation in physiological conditions. Heat shock proteins are involved in apoptosis inhibition, acting at several steps of both extrinsic and intrinsic pathways. In particular in the intrinsic pathway they are involved both at mitochondrial and at the apoptosome levels (30). Heat shock protein 90 and 70 , induced by several toxic stimuli, prevent apoptosome formation binding to Apaf1 and inhibiting its oligomerization $(31,32)$. However, Hsp70's direct role in apoptosome inhibition is challenged by the observation that this interaction might be an artifact, and that it has no effect in cells where cytochrome $c$ has been released. Thus, Hsp70 might act only upstream of the mitochondria (33).

TUCAN (Tumor-Up-regulated CARD-containing Antagonist of caspase-9) and its isoform TUCAN-54, bind procaspase- 9 by their CARD domain, thus inhibiting the interaction with Apaf1 $(34,35)$.

IAPs (the Inhibitor of Apoptosis Proteins), other proteins involved in apoptosome regulation, are characterized by the presence of the BIR (Baculoviral IAP Repeat) domain, that allows them to bind caspases. They are sub-divided into three classes: the first class is characterized by the presence of BIR domains and the Ring finger motif (XIAP, ML-IAP, cIAP1, cIAP2, etc.); the second class has three BIR domains (NAIP); the third has one BIR domain (survivin) (36).

XIAP (X-linked Inhibitor of Apoptosis Protein) binds active caspase- 3 and caspase-7 through the BIR2 domain, whereas caspase-9 is bound, in its inactive monomeric form, by the third BIR domain (37). The Ring domain, which has E3 ubitiquin ligase activity, promotes ubiquitination and subsequent degradation of caspase-3 and -9 (37).

There are contrasting data on IAPs role. In fact some studies mainly based on GST-fusion proteins demonstrated that they bind and inhibit caspases $(38,39)$. However, recent experiments have revealed that many IAPs are not able to inhibit caspases in physiological concentrations (40); in particular cIAP1 and cIAP2 are able to bind, but not to inhibit caspases, probably because of the lack of important sites for caspase inhibition (41). The role of survivin in the direct inhibition of caspases is questionable, too $(42,43)$. Thus, as of now XIAP seems the only direct caspase inhibitor among the IAPs (44). It has been proposed that IAPs could have a role in interacting with XIAP antagonists, so leading free XIAP to take on its inhibiting role, or in causing degradation of caspases or XIAP antagonists by ubiquitination. It has been also discovered by point mutations that XIAP is able to inhibit apoptosis when it loses the ability to bind caspase- 3 and caspase- 9 but retains its ability to bind the antagonist DIABLO (45). Thus the interaction with antagonists seem to have a relevant role in IAPs function.

Inhibitors of IAPs also exist. For example, Smac/ DIABLO and Omi/HtrA2, released from intermembrane space when mitochondria are damaged, are able to interact with and inhibit IAPs (46). XIAP is inhibited by both Smac/ DIABLO and Omi/HtrA2.

PHAPI, also known as Mapmodulin (Putative HLADR-Associated Protein), is a pro-apoptotic factor. Previous studies have shown its role in increasing caspase-3 activity (47). Recent studies have demonstrated that it is overex- 
pressed in breast cancer cells, where it causes a great sensitivity to cytochrome $c$. In fact, microinjecting cytochrome $c$ into these cells causes cell death through an increased association of caspase-9 to Apaf1 and subsequent activation of effector caspases (48).

The apoptosome formation is also influenced by intracellular nucleotides, potassium and calcium concentration. As regards intracellular nucleotides, it has been demonstrated that they have an inhibitory role on apotosome in normal conditions $(49,50)$. In particular, they bind to the lysine residues of cytochrome $c$, so preventing its binding with Apaf1. In physiological conditions, nucleotide concentration prevents the mitochondrial release of small quantities of cytochrome $c$ from activating the apoptosome. However, under apoptotic stimuli, their concentration decreases, as observed in previous experiments, so permitting apoptosome formation (49).

Potassium seems to have a similar role. It has been demonstrated that normal potassium concentration in the cell inhibits Apaf1 oligomerization. This effect is antagonized in a concentration dependent manner by cytochrome $c$, so the assembly of the apoptosome requires a massive release of cythocrome $c$ from mitochondria (51).

Moreover, it has been recently demonstrated that calcium binds to monomeric Apaf1, so blocking apoptosome assembly by impeding the nucleotide exchange (52).

\section{PHARMACOLOGICAL APOPTOSIS REGULATION IN PRECLINICAL AND CLINICAL DEVELOPMENT}

Numerous novel approaches are currently being pursued employing recombinant biomolecules, antisense strategies, gene therapy or classical organic and combinatorial chemistry to target specific apoptotic regulators. All these approaches aim to correct excessive or deficient cell death in human diseases or in animal/cellular models of disease.

In general, the upregulation (or downregulation) of antiapoptotic proteins leads to a prevention (or induction) of apoptosis which can be solved through inhibitors (or activators) able to bind and modify their activity. Hence, there is an enormous interest in devising therapeutic strategies to modulate key molecules involved in life-death decision in the cell. We will focus here on some of these important key molecules and discuss them as targets in apoptosis-based therapies at the preclinical and clinical stage.

\section{Bcl-2 as Target of Drug Design}

Bcl-2, discovered because of the translocation $t$ (14:18) present in many patients affected by follicular lymphoma, was the first oncogene to cause cancer inhibiting apoptosis and not inducing cell proliferation (53). It is overexpressed in several tumors (54) and is also associated with resistance to chemotherapy. There are some exceptions where its overexpression is associated with better prognoses and in other cases, where its downregulation does not affect tumor growth. This is probably caused by $\mathrm{Bcl}-2$ involvement in both apoptosis and cell cycle control (55). Despite this, it remains a good target for drug design (Table I).

The Bcl-2 family members regulation is not clear and several models have been proposed (56). According to rheostat model (57), Bcl-2 family members are involved in a complex network of direct and indirect interactions. It has also been proposed that $\mathrm{BH} 3$-only proteins, activated in response to different apoptotic stimuli and characterized by different affinity for the Bcl-2 pro-apoptotic proteins, could bind them impeding their inhibitory effect on Bcl-2 anti-apoptotic factors. According to another model, some BH3-only proteins could act as "derepressors" and others as "direct activators." Derepressors bind to Bcl-2 antiapoptotic proteins, inhibiting them and leaving direct activators free to interact with Bax and Bak (11). Several studies are focused on Bcl-2 inhibition, in particular, developing small molecules and peptides which mimic proapoptotic $\mathrm{BH} 3$-only proteins.

Studies using small molecules like HA14-1 (58), antymicin A (59), tetrocarcin A (TCA; 60), chelerythrine, a natural benzophenanthridine alkaloid, show that they induce apoptosis in cells overexpressing $\mathrm{Bcl}-2$ and $\mathrm{Bcl}-\mathrm{X}_{\mathrm{L}}(61)$, although a recent study (62) has demonstrated that the mechanism of action of these compounds (HA14-1, gossypol, chelerythrine and antymicin A) is independent of Bax and Bak. Therefore they could not act solely as $\mathrm{BH} 3$ mimetics, consequently, the molecular mechanism by which these reagents induce cell death remains unclear.

Recent preclinical studies evidenced that gossypol (63), a lipid soluble polyphenolic constituent of cottonseed oil, binds to $\mathrm{Bcl}-\mathrm{X}_{\mathrm{L}}$ and, with less affinity, to Bcl-2, causing their downregulation.

The clinical study (64) investigated the safety and efficacy of oral gossypol in a heavily pretreated patient population with metastatic breast cancer. Gossypol is safe, but demonstrated limited activity in doxorubicin and taxane refractory metastatic breast cancer. At dosage of $40 \mathrm{mg}$ /day in divided dose the agent was well tolerated and the toxicities experienced by this patient population consisted primarily of mild nausea, fatigue, emesis, and diarrhea. However, no therapeutic responses were observed. Interestingly, gossypol appears to affect the expression of Rb protein and cyclin D1 in breast cancer metastases suggesting a potential role for gossypol as a modulator of cell cycle regulation.

FDA (Food and Drug Administration) approved gossypol for phase I clinical trial (ClinicalTrials.gov idenfier NCT0039043) for patients with newly diagnosed glioblastoma multiform and for phase II clinical trial (ClinicalTrials.gov identifier NCT00440388) for patients with diagnosed follicular lymphoma.

ABT-737, another inhibitor molecule, is more specific for Bcl-2 and showed efficacy against small-cell lung carcinoma (65), lymphoma (66) and myeloma (67). New small organic inhibitors specific for Bcl-2 have been recently developed (68). Epigallocatechin-3-gallate (EGCG), a major constituent polyphenol in green tea extract, was found to have a pronounced growth inhibitory effect on cancer cells. Many studies in vitro confirmed that EGCG significantly downmodulates the expression of Bcl-2 family proteins (69-71).

In an initial clinical study (Phase I-II) currently recruiting patients (ClinicalTrials.gov identifier NCT0016635), healthy volunteers and patients with chronic limphocytic leukemia are being treated with oral green tea extract. This clinical trial is for patients with early stage chronic lymphocitic leukemia who do not require active chemoterapy 
Table I. Preclinical and Clinical Therapeutics Targeting Bcl-2 Protein

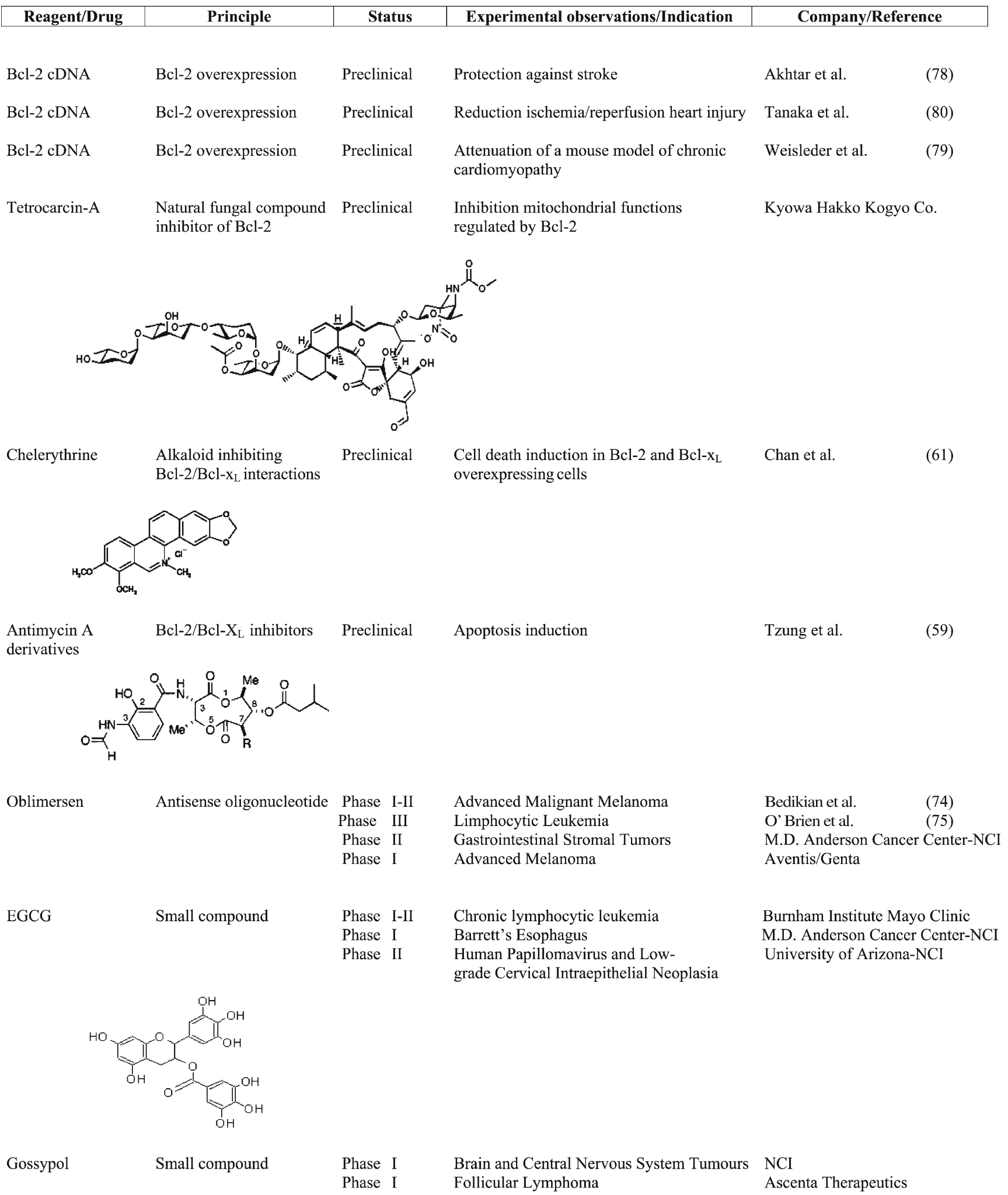<smiles>Cc1cc2c(C(C)C)c(O)c(O)c(C=O)c2c(O)c1-c1c(C)cc2c(C(C)C)c(O)c(O)c(C=O)c2c1O</smiles> 
treatment. The goal of this study is: (1) to determine the dose immediately below the level that causes too many side effects (the best dose); (2) to evaluate effectiveness of the treatment every month during treatment.

Recently, FDA approved EGCG for phase I clinical trial (ClinicalTrials.gov identifier NCT00233935, studying the side effects and best dose of green tea extract in preventing esophageal cancer in patients with Barrett's esophagus) and for phase II clinical trial (www.ClinicalTrials.gov identifier NCT00303823, studying green tea extract to see how well it works compared to a placebo in preventing cervical cancer in patients with human papillomavirus and low-grade cervical intraepithelial neoplasia).

Another promising technique is the use of antisense RNAs, which, by binding specific mRNAs target, cause their cleavage by RNase-H (72). The antisense Bcl-2 oblimersen, is an 18-mer phosphorothioate oligonucleotide that binds to the first six codons of the human Bcl-2 mRNA. Several studies show that the downregulation of $\mathrm{Bcl}-2$ by oblimersen leads to apoptosis activation (73). The combination treatment with oblimersen and an anticancer drug increased the chemotherapeutic effect in some types of tumor (73). In patients with advanced melanoma, for example, the addition of oblimersen to dacarbazine (used in therapy for methastatic melanoma) improved response to this drug without an increasing toxicity. In this melanoma study (74) the patients with advanced melanoma have been randomly assigned to treatment with dacarbazine $\left(1,000 \mathrm{mg} / \mathrm{m}^{2}\right)$ alone or preceded by a 5-day continuous intravenous infusion of oblimersen $\left(7 \mathrm{mg} \mathrm{kg} \mathrm{kg}^{-1}\right.$ $\mathrm{d}^{-1}$ ) every 3 weeks for up to eight cycles. The primary endpoint of this clinical trial was overall survival and the results have been very promising. The addition of oblimersen to dacarbazine yielded a trend toward improved survival at 24-month follow-up and significant increases in progression-free survival, overall response, complete response, and durable response.

In patients with relapsed or refractory chronic lymphocytic leukemia (75) the addition of oblimersen to fludarabine plus cyclophosphamide significantly increased the rate of complete response plus nodular partial responses. These responses were durable and significantly longer than were those achieved with chemotherapy alone.

We feel obliged to inform the reader that recent papers have debated the results on oblimersen and Bcl-2 downregulation. In fact, Kim et al. (73) demonstrated that the oblimersen activity is dependent on an immune stimulatory effect rather than on Bcl-2 downregulation.

Also, Tan et al. $(76,77)$ demonstrated that oblimersen, induces apoptosis in melanoma and other cancer cells, and this apoptosis happens before and in the absence of the downregulation of Bcl-2 and thus seems to be Bcl-2-independent.

In addition to approaches aimed at downregulating Bcl-2 protein, its selective overexpression might be a valuable strategy for the protection against premature cell death.

Pioneering work in the area of Bcl-2 upregulation has been performed in a mouse model of chronic cardiomyopathy and stroke (78-80).

\section{Caspases and Their Regulators}

Experimental evidence suggests that inhibition of caspase activity blocks cell death in many models of human disease, including various neurodegenerative disorders, stroke, heart attack and liver injury. Therefore, caspase inhibitors are a promising pharmacological tool providing treatments for stroke and other human diseases mentioned above (Table II).

Several caspase inhibitors are currently in the preclinical stage. The Merck Frosst Center recently developed a small reversible caspase-3 inhibitor, M-826. In a mouse model of hypoxia-ischemia M-826 blocked brain tissue damage (81). Also, in a mouse model of Huntington's disease, the same inhibitor prevented striatal neuron death (82).

Even before the discovery of the role of caspases in apoptosis, several companies started drugs programs aimed at screening for caspase- 1 inhibitors in order to suppress IL13. Consequently we cannot consider the anti-apoptotic activity of pan-caspase inhibitors without taking into account their effect on the caspase-1 as anti-inflammatory compounds.

A successful compound which is already in phase II of clinical studies is the irreversible pan-caspase inhibitor, IDN6556 (IDUN Pharmaceuticals). IDN-6556 is considered a candidate for the treatment of acute-tissue injury disease. In a first clinical study, healthy volunteers and patients with impaired hepatic function were treated with intravenous infusion of IDN-6556. Doses up to $1.5 \mathrm{mg} / \mathrm{kg}$ for 7 days were well tolerated. Orally given IDN-6556 is currently being tested in phase II clinical trials for the treatment of $\mathrm{HCV}$ infection, and further studies are planned for nonalcoholic steatohepatitis and other hepatobiliar diseases. Vertex/Aventis has developed VX-799, another pan-caspase inhibitor. VX-799 is one of the first small molecule caspase inhibitors to be advanced into development, and represents a completely novel approach to treating sepsis patients, for whom limited treatment options are available. This drug is currently in phase I of clinical trial.

The activation of caspases, on the other hand, might be a valuable pharmacological strategy, especially for the therapy of human cancer. Because the success of gene delivery approaches is still limited, pharmacological activation of cellular caspases by small cell-permeable compounds could provide a more efficient tool for targeting cancer cells.

In several cell types, it was previously shown that soluble RGD peptides induce apoptosis, which was first attributed to the loss of cell attachment and survival signalling $(83,84)$. Buckley et al. (85), however, demonstrated that RGD peptides induce caspase-3 activation independently of integrins. Recently Merck developed a RGD-based candidate drug to inhibit neo-formation of tumor blood vessels.

Maxim Pharmaceuticals are currently evaluating the therapeutic potential of a small molecule which activates caspases, MX-2060, a derivative of gambogic acid, a natural product extracted from Garcinia hurbury (86) and tested as a potential anticancer agent in human cancer xenograft animal models.

Some attempts have also been made to directly introduce caspase- 3 into tumoral cells by fusing the protein with an antibody or by an expression plasmid. Jurkat cells, transfected with a plasmid encoding caspase- 3 fused with an antibody against an antigen (HER2) widely expressed on the surface of tumor cells (breast, ovary, stomach carcinoma), were able to produce and secrete the fusion protein called 
Table II. Preclinical and Clinical Therapeutics Targeting Caspases and Its Modulators

\begin{tabular}{|l|l|l|l|l|}
\hline Reagent/Drug & Principle & Status & Experimental observations/Indication & Company/Reference \\
\hline
\end{tabular}

\begin{tabular}{|c|c|c|c|c|}
\hline RGD peptides & Caspase activator & Preclinical & Apoptosis induction in tumor cell line & Merck Frosst \\
\hline M-826 & $\begin{array}{l}\text { Reversible caspase- } 3 \\
\text { inhibitor }\end{array}$ & Preclinical & $\begin{array}{l}\text { Protection against neonatal hypoxia-ischemia } \\
\text { Rescue neuron in Huntington'disease mouse model }\end{array}$ & Merck Frosstt \\
\hline
\end{tabular}

\begin{tabular}{|c|c|c|c|c|}
\hline Ad-G/Casp3 & $\begin{array}{l}\text { Adenoviral chemically } \\
\text { inducible caspase } 3\end{array}$ & Preclinical & $\begin{array}{l}\text { Reduction in tumor growth in a prostate cancer } \\
\text { mouse model }\end{array}$ & Shariat et al. (88) \\
\hline MX-2060 & Caspase activator & Preclinical & $\begin{array}{l}\text { Potential anticancer agent, tested in human cancer } \\
\text { xenograft animal models }\end{array}$ & Maxim Pharmaceutical \\
\hline LY2181308 & $\begin{array}{l}\text { Survivin antisense } \\
\text { oligonucleotide }\end{array}$ & Phase I-II & Advanced Hepatocellular Carcinoma & Isis/Eli Lilly \\
\hline Embelin & XIAP-inhibitor & Preclinical & $\begin{array}{l}\text { Enhancement cisplatin induced apoptosis } \\
\text { in prostate cancer cells }\end{array}$ & Sun et al. \\
\hline
\end{tabular}<smiles>CCCCC1=C(O)C(=O)C=C(O)C1=O</smiles>

\begin{tabular}{|c|c|c|c|c|}
\hline AEG35156/ & Antisense & Phase I & Advanced Cancer & Aegera/Hybridon \\
\hline GEM640 & oligonucletide & Phase I & $\begin{array}{l}\text { Locally Advanced, Metastatic, } \\
\text { or Recurrent Solid Tumors }\end{array}$ & NCI of Canada \\
\hline IDN-6556 & Caspase inhibitor & Phase II & $\begin{array}{l}\text { Chronic Hepatitis C (HCV) } \\
\text { Acute alchoolic hepatitis }\end{array}$ & $\begin{array}{l}\text { Idun Pharmaceuticals } \\
\text { Idun Pharmaceuticals }\end{array}$ \\
\hline
\end{tabular}

VX-799

Caspase inhibitor

Phase I

Effective in sepsis and neuronal cell death

Vertex/Aventis

Companies: Aventis (www.aventis.com), Idun Pharmaceuticals, Inc. (www.idun.com), Maxim Pharmaceuticals (www.maxim.com), Merck Frosst Canada \& Co. (www.merck-frosst.ca), Vertex pharmaceuticals, Inc. (www.vpharm.com), Eli Lilly and Company (www.lilly.com), NCI (National Cancer Institute, www.cancer.gov), NCI of Canada (National Cancer Institute of Canada www.ncic.cancer.ca); Ascenta Therapeutics (www.ascenta.com); Aegera Therapeutics Inc. (www.aegera.com), Hybridon (www.hybridon.com); Genta Incorporated (www.genta.com); Kyowa Hakko Kogyo Co., Ltd (www.kyowa.co.jp); ISIS Pharmaceuticals (www.isispharm.com); Hybridon (www. hybridon.com). 
immunocasp-3. This product selectively binds the antigenoverexpressing cancer cells; it is internalized, subjected to lysosomal cleavage and released into the cytosol, where it leads to cell death. This fusion protein also causes suppression of HER2-overexpressing tumors in vivo (87). Some attempts have also been made in order to obtain adenoviral constructs expressing caspase-3 whose expression in cells was very effective in inducing apoptosis (88).

In some tumors, caspase activity is prevented by the overexpression of specific inhibitors. In particular, XIAP is overexpressed in some tumors (37), preventing caspase activity and causing chemoresistance. This makes it one of the most promising targets in cancer therapy.

Several antisense oligonucleotides specific for XIAP mRNA are effective in vitro and some of them are in different phases of clinical trials. For example, antisense oligonucleotide AEG35156/GEM 640 (Aegera Therapeutics/Hybridon) reduces XIAP levels and sensitizes tumors to chemotherapy. It is undergoing multiple phase I clinical trials in cancer as a single agent or in combination with other drugs (89).

A clinical study is ongoing (ClinicalTrials.gov identifier NCT00385775). This study is designed to find the maximum tolerated dose, safety and toxicity profile, and to identify any dose limiting toxicities of AEG35156 administered in 2$\mathrm{h}$ infusions to patients with advanced cancers. This is a Phase I-II, single-arm, open-label, dose escalation study to establish the recommended dose and activity of AEG35156 administered as an 2-h daily infusion over 3 days initially followed by weekly 2-h intravenous infusions in patients with advanced cancers.

Primary outcome measures of this study is to determine the dose level at which AEG35156 is well tolerated based upon development of toxicities during the first cycle of therapy unless cumulative or delayed toxicity is encountered. Secondary outcome measures of this study is to evaluate: (1) the impact of AEG35156 on inhibition and apoptosis in tumor biopsies or circulating tumour cells; (2) the occurrence of XIAP knockdown in peripheral blood mononuclear cells; (3) the plasma pharmacokinetic profile of AEG35156; (4) the possible anti-tumor activity of XIAP.

Recently, FDA approved AEG35156 for phase I clinical trial (www.ClinicalTrials.gov identifier NCT00372736, studying the side effects and best dose of AEG35156 when given together with docetaxel in treating patients with locally advanced, metastatic, or recurrent solid tumors).

The study of XIAP antagonists and the analysis of structure and function of XIAP domains is also relevant here, in order to permit the designing or identifying of inhibitor peptides able to bind a XIAP specific domain. For example, it is known that XIAP antagonists, such as Smac/DIABLO and Omi/Htra2 (90), share the IBM (IAP Binding Motif); and it is also known that peptides corresponding to the $\mathrm{N}$ terminal of Smac/DIABLO sensitize lung cancer to cisplatin and taxol (91). Recently other antagonists have been identified, which reside in mitochondria and contain the IBM (92) and they should be useful for studying XIAP regulation. Based on these observations, several studies were switched to obtain Smac/DIABLO peptides or IBM domains fused with carriers, able to bind and inhibit XIAP and, more recently, to also obtain specific inhibitors for BIR2 or BIR3 domains (37). One of the most recent is embelin, a smallmolecular weight inhibitor discovered by screening of a herbal medicine three-dimensional database (93). Embelin binds to XIAP BIR3 domain and inhibits cell growth, induces apoptosis, and activates caspase-9 in prostate cancer cells with high levels of XIAP (94).

AFP (Alpha-FetoProtein) promotes growth, but it is also involved in tumor inhibition.

Its role in tumor growth inhibition and suppression has been observed using a derived AFP-synthetic peptide (96). However, AFP mechanism of action is still unclear. Some studies have shown that AFP leads cancer cells, but not control cells, to death through caspase-3 (95). In a cell-free system AFP has been demonstrated to facilitate the release of caspase-3 from the apoptosome, probably displacing cIAP2 (97). Recently, it has been demonstrated that AFP penetrates tumor cells, since they express AFP receptors on their surface, and that it disrupts the association between XIAP and caspase-3. AFP also binds free XIAP, so impeding its binding to caspase-3 (98). More studies, not only in vitro, are required to clarify this aspect.

Survivin is detected in many tumors (99), whereas it is expressed only in a few adult tissues (100). Even if its role in direct caspase regulation is unclear, it seems to induce chemoresistance in tumor cells making it an interesting target for drug design. The antisense oligonucleotide LY2181308 (ISIS/Eli Lilly), specific for survivin, is being evaluated in phase I clinical trials (www.ClinicalTrials.gov Identifier NCT00415155).

The primary objective of this clinical study, sponsored by Eli Lilly and Company, will be to estimate the time to progressive disease for patients with advanced hepatocellular cancer who receive LY2181308.

Primary Outcome Measures will be: a) the recommended dose of LY2181308 in the advanced hepatocellular cancer (HCC) population; b) time to progression for patients with advanced HCC who have received LY2181308.

Secondary Outcome Measures will be: (a) overall survival time; (b) progression-free survival; (c) time to progression of cancer symptoms; (d) safety, response rate, pharmacokinetics, effect on circulating tumor cells and survivin expression.

\section{Interfering with Apoptosome Formation}

As outlined above, Apaf1/caspase-9 apoptosome formation is a crucial event in the apoptotic cascade. Therefore, the identification of new potential drugs which prevent (or stabilize) the formation of active apoptosome complex could be a good strategy for the treatment of diseases characterized by excessive (or insufficient) apoptosis.

Recently, taurine (2-aminoethanesulfonic acid) has been found to prevent ischemia-induced apoptosis in cardiomyocytes through its ability to inhibit Apaf1/caspase-9 apoptosome formation without preventing mitochondrial dysfunction under ischemic conditions (101). The possible mechanism by which taurine inhibits the apoptosome formation was identified as being capable of reducing the expression of caspase-9, a fundamental component of apoptosome.

Several active compounds interfering with apoptosome assembly have been recently identified by high throughput screening of a chemical library. In particular, oligomers of $\mathrm{N}$ alkylglycines also known as peptoids, are an interesting family of non-natural molecules which exhibit many biolog- 
ical activities. Among these compounds, peptoid 1a binds reversibly to Apaf1, precluding the recruitment and activation of procaspase-9 and, consequently, inhibiting the apoptotic cascade (102). Conversely, the possibility of increasing apoptosome complex formation is relevant in cancer therapy. To date the studies have been focused in particular on Apaf1 and/or caspase-9 expression levels in several tumors; for example, it is well-known that Apaf1 gene expression is altered in leukemia cells (103), bladder cancer (104), gastrointestinal tumors (105), glioblastoma (106) and germ line tumor (107). Moreover, the Apaf1 gene is silenced in some melanoma cell lines (108) but not in others (109), probably because of different cell culture conditions, protein extraction antibody usage, or different sites of origin. In fact, melanoma is heterogeneous (110).

Some efforts have also been made to restore Apaf1 or caspase-9 levels. For instance LAQ824, a HDAC (histone deacetylases deacetylate the nucleosomal histones reducing gene expression) inhibitor family, causes apoptosis in lung cancer cells, but not in fibroblasts, promoting, in particular, mitochondrial pro-apoptotic factor release and also inducing Apaf1 and caspase-9 transcription (111). Another study was carried out to find a correlation between Apaf1 and caspase-9 levels and chemoterapy resistance. It revealed that there was not a strong correlation between these proteins levels and sensitivity to drugs in vitro and that the only role that Apaf1 and caspase-9 levels seemed to have is in slowing down cell death. (112).

It is important to highlight that some studies suggest that Apaf1 and caspase-9 have other roles independent of the apoptosome; therefore, altering their levels could lead to altering cellular function.

In particular, the evidence that: (a) resectable non-small cell lung cancers containing high levels of Apaf1 in an atypical nuclear localization have a favorable prognosis (113); (b) cisplatin induced translocation of Apaf1 from the cytoplasm to the nucleus (113); and (c) the nuclear Apaf1 translocation was independent from the apoptosis-related nuclear permeabilization (114) led us to suppose nonapoptotic role(s) of Apaf1.

\section{CONCLUSIONS}

Emerging knowledge about the proteins that constitute the apoptotic machinery and the definition of molecular structure of the apoptosome complex has revealed new potential targets for molecular therapy. Despite very encouraging experimental data in vitro and even in animal models, several problems remain to be solved and limit the use of experimental drugs in clinical practice.

A major pharmacological problem frequently encountered by the development of brain-active anti-apoptotic drugs is the relative impermeability of the brain-blood barrier for caspase inhibitors currently in use. Also, caspase inhibitors may exhibit activity in vivo, even when they are applied postinsult. However, in many acute diseases (stroke, heart attack) pharmacological treatment needs to be available immediately. The apoptosome, considered as a complex, is an emerging pharmacological target, even though only few compounds targeting it have been tested and none of these have yet been approved by FDA for starting clinical trials.
The discovery of apoptosome inhibitors will provide a new therapeutical tool for the treatment of apoptosismediated disease. Of particular importance are those new compounds able to inhibit apoptosome stability and activity, by acting on intracellular protein-protein interactions without altering the transcriptional levels of the apoptosome components.

\section{ACKNOWLEDGMENTS}

We are grateful to Elisabetta Ferraro for the drawings in Fig. 1 and to Martin Wilmot Bennett for excellent editorial work. Our research is supported by Fondazione Telethon, Compagnia di San Paolo, MIUR and AIRC. FC is an Associate Telethon Scientist.

\section{REFERENCES}

1. A. H. Wyllie, J. F. Kerr, and A. R. Currie. Cell death: the significance of apoptosis. Int. Rev. Cyt. 68:251-306 (1980).

2. P. Fuentes-Prior and G. S. Salvesen. The protein structures that shape caspase-activity, specificity, activation and inhibition. Biochem. J. 384:201-232 (2004).

3. D. R. Green and G. Kroemer. The pathophysiology of mitochondrial cell death. Science 305:626-629 (2004).

4. K. Schulze-Osthoff, D. Ferrari, M. Los, S. Wesselborg, and M. E. Peter. Apoptosis signaling by death receptors. Eur. J. Biochem. 254:439-459 (1998).

5. M. E. Peter and P. H. Krammer. The CD95 (Apo-1/Fas) DISC and beyond. Cell Death Differ 10no. 1, 26-35 (2003).

6. L. Bouchier-Hayes, L. Lartigue, and D. D. Newmeyer. Mitochondria: pharmacological manipulation of cell death. $J$. Clin. Invest. 115no. 10, 2640-2647 (2005).

7. Y. Tsujimoto, T. Nakagawa, and S. Shimizu. Mitochondrial membrane permeability transition and cell death. Biochim. Biophys. Acta 1757:1297-1300 (2006).

8. J. M. Adams and S. Cory. The Bcl-2 protein family: arbiters of cell survival. Science 281:1322-1326 (1998).

9. E. Er, L. Oliver, P. F. Cartron, P. Juin, S. Manon, and M. Vallette. Mitochondria as the target of the pro-apoptotic protein Bax. Biochim. Biophys. Acta 1757no. 9-10, 1301-1311 (2006).

10. G. Kroemer, L. Galluzzi, and C. Brenner. Mitochondrial membrane permeabilization in cell death. Physiol. Rev. 87no. 1, 99-163 (2007).

11. V. Labi, M. Erlacher, S. Kiessling, and A. Villunger. BH3-only proteins in cell death initiation, malignant disease and anticancer therapy. Cell Death Differ 13:1325-1338 (2006).

12. P. G. Ekert, S. H. Read, J. Silke, V. S. Marsden, H. Kaufmann, C. J. Hawkins, R. Gerl, S. Kumar, and D. L. Vaux. Apaf-1 and caspase-9 accelerate apoptosis, but do not determine whether factor-deprived or drug-treated cells die. J. Cell Biol. 165no. 6, 835-842 (2004).

13. J. C. Goldstein, N. J. Waterhouse, P. Juin, G. I. Evan, and D. R. Green. The coordinate release of cytochrome c during apoptosis is rapid, complete and kinetically invariant. Nat. Cell Biol. 2no. 3, 156-162 (2000).

14. N. J. Waterhouse, J. C. Goldstein, O. Ahsenvon, M. Schuler, D. D. Newmeyer, and D. R. Green. Cytochrome c maintains mitochondrial transmembrane potential and ATP generation after outer mitochondrial membrane permeabilization during the apoptotic process. Cell Biol. 153no. 2, 319-328 (2001).

15. A. Colell, J. E. Ricci, S. Tait, S. Milasta, U. Maurer, L. Bouchier-Hayes, P. Fitzgerald, A. Guio-Carrion, N. J. Waterhouse, C. W. Li, B. Mari, P. N. Barbry, D. D. Newmeyer, H. M. Beere, and D. R. Green. GAPDH and autophagy preserve survival after apoptotic cytochrome $\mathrm{c}$ release in the absence of caspase activation. Cell 129no. 5, 983-997 (2007). 
16. H. E. Kim, F. Du, M. Fang, and X. Wang. Formation of apoptosome is initiated by cytochrome c-induced dATP hydrolysis and subsequent nucloetide excahnge on Apaf1. Proc. Natl. Acad. Sci. U. S. A. 102no. 49, 17545-17550 (2005).

17. J. Rodriguez and Y. Lazebnik. Caspase-9 and Apaf-1 form an active holoenzyme. Genes Dev. 13:3179-3184 (1999).

18. Q. Bao and Y. Shi. Apoptosome: a platform for the activation of initiator caspases. Cell Death Differ. 14no. 1, 56-65 (2007).

19. G. S. Salvesen and V. M. Dixit. Caspase activation: the induced-proximity model. Proc. Natl. Acad. Sci. U. S. A. 96no. 20, 10694-10697 (1999).

20. M. Muzio, B. R. Stockwell, H. R. Stennicke, G. S. Salvesen, and V. M. Dixit. An induced proximity model for caspase8 activation. J. Biol. Chem. 273no. 5, 2926-2930 (1998).

21. Y. Shi. Caspase activation: revisiting the induced proximity model. Cell 117:855-858 (2004).

22. M. Renatus, H. R. Stennicke, and G. S. Salvesen. Dimer formation drives the activation of the cell death protease caspase-9. Proc. Natl. Acad. Sci. U. S. A. 98:14250-14255 (2001).

23. C. Pop, J. Timmer, S. Sperandio, and G. S. Salvesen. The apotosome activates caspase-9 by dimerization. Mol. Cell 22:269-275 (2006).

24. Y. Chao, E. N. Shiozaki, S. M. Srinisavula, D. J. Rigotti, R. Fairman, and Y. Shi. Engineering a dimeric caspase-9: a reevaluation of the induced proximity model for caspase activation. PLos Biol. 3no. 6, e183, 2005 (2005).

25. Q. Yin, H. H. Park, J. Y. Chung, S. C. Lin, Y. C. Lo, L. S. Gracada, X. Jiang, and H. Wu. Caspase-9 holoenzyme is a specific and optimal procaspase-3 processing machine. Mol. Cell 22:259-268 (2006).

26. D. Acehan, X. Jiang, D. G. Morgan, J. E. Heuser, X. Wang, and C. W. Akey. Three-dimensional structure of the apoptosome: implications for assembly, procaspase-9 binding and activation. Mol. Cell 9:423-432 (2002).

27. X. Yu, D. Acehan, J. F. Menetret, C. R. Booth, S. J. Ludtke, and S. J. Riedl. A structure of the human apoptosome at $12.8 \mathrm{~A}$ resolution provides insights into this cell death platform. Structure 13:1725-1735 (2005).

28. A. V. Diemand and A. Lupas. Modeling AAA+ ring complexes from monomeric structures. J. Struct. Biol. 156no. 1, 230-243 (2006)

29. J. Nakabayashi and A. Sasaki. A mathematical model for apoptosome assembly: the optimal cytochrome c/Apaf1 ratio. $J$. Theor. Biol. 242:280-287 (2006).

30. H. M. Beere. Death versus survival: functional interaction between the apoptotic and stress-inducible heat shock protein pathways. J. Clin. Invest. 115no. 10, 2633-2639 (2005).

31. A. Saleh, S. M. Srinivasula, L. Balkir, P. D. Robbins, and E. S. Alnemri. Negative regulation of the Apaf1 apoptosome by Hsp70. Nat. Cell Biol. 3no. 9, 839-843 (2000).

32. P. Pandey, A. Saleh, A. Nakazawa, S. Kumar, S. M. Srinisavula, V. Kumar, R. Weichselbaum, C. Nalin, E. S. Alnemri, D. Kufe, and S. Kharband. Negative regulation of cytochrome-c-mediated oligomerization of Apaf-1 and activation of procaspase-9 by heat shock protein 90. EMBO J. 19no. 16, 4310-4322 (2000).

33. R. Steel, J. P. Doherty, N. K.Buzzard, C. J. Clemons, and R. L. Hawkins. Hsp72 inhibits apoptosis upstream of the mitochondria and not through interactions with Apaf1. $J$. Biol. Chem. 279no. 49, 51490-51499 (2004).

34. N. Pathan, H. Marusawa, M. Krajewska, S. Matsuzawa, H. Kim, K. Okada, S. Torii, S. Kitada, S. Krajewski, K. Welsh, F. Pio, A. Godzik, and J. C. Reed. TUCAN, an antiapoptotic caspaseassociated recruitment domain family protein overexpressed in cancer. J. Biol. Chem. 276no. 34, 32220-32229 (2001).

35. M. Yamamoto, T. Torigoe, Y. Kamiguchi, K. Nakanishi, C. Nabeta, H. Asanuma, T. Tsuruma, T. Sato, F. Hata, T. Ohmura, K. Yamaguchi, T. Kurotaki, K. Hirata, and N. Sato. A novel isoform of TUCAN is overexpressed in human cancer tissues and suppresses both caspase- 8 and caspase- 9 mediated apoptosis. Cancer Res. 65no. 19, 8706-8714 (2005).

36. A. D. Schimmer. Inhibitor of apoptosis proteins: translating basic knowledge into clinical practice. Cancer Res. 64:7163-7190 (2004).
37. A. D. Schimmer, S. Dalili, R. A. Batey, and J. Riedl. Targeting XIAP for the treatment of malignancy. Cell Death Differ. 13:179-188 (2006).

38. J. K. Mayer, Z. Lahoua, N. H. Gendron, R. Fetni, A. Johnston, J. Davoodi, D. Rasper, S. Roy, R. S. Slack, D. W. Nicholson, and A. E. MacKenzie. The neuronal apoptosis inhibitory protein is a direct inhibitor of caspases 3 and 7. J. Neurosci. 180no. 1, 91-101 (2002).

39. D. Vucic, H. R. Stennicke, M. T. Pisabarro, G. S. Salvesen, and V. S. Dixit. ML-IAP, a novel inhibitor of apoptosis that is preferentially expressed in human melanoma. Curr. Biol. 10:1359-1366 (2000).

40. B. A. Callus and D. L. Vaux. Caspase inhibitors: viral, cellular and chemical. Cell Death Differ. 14:73-78 (2007).

41. P. B. Eckelman and G. S. Salvesen. The human anti-apoptotic proteins cIAP1 and cIAP2 bind but do not inhibit caspases J. Biol. Chem. 281no. 6, 3254-3260 (2006).

42. S. Shin, B. J. Sung, Y. S. Cho, H. J. Kim, N. C. Ha, J. I. Huang, C. W. Chung, Y. K. Jung, and B. H. Oh. An anti-apoptotic protein human survivin is a direct inhibitor of caspase-3 and -7 . Biochemistry 40:1117-1120 (2001).

43. D. P. Banks, J. Plescia, D. C. Altieri, J. Chen, S. H. Rosenberg, H. Zhang, and S. C. Ng. Survivin does not inhibit caspase-3 activity. Blood 95:1435-1442 (2000).

44. B. P. Eckelman, G. S. Salvesen, and F. L. Scott. Human inhibitor of apoptosis proteins: why is the black sheep of the family. EMBO Rep. 7no. 10, 988, 2006 (2006).

45. J. Silke, C. J. Hawkins, P. G. Ekert, J. Chew, C. L. Day, M. Pakush, A. M. Verhagen, and D. L. Vaux. The antiapoptotic activity of XIAP is retained upon mutation of both the caspase-3 and caspase-9-interacting sites. J. Biol. Chem. 157no. 1, 115-124 (2002).

46. A. M. Verhagen, J. Silke, P. G. Ekert, M. Pakush, H. Kaufmann, L. M. Connolly, C. L. Day, A. Tikoo, R. Burke, C. Wrobel, R. L. Moritz, Simpson, and D. L. Vaux. HtrA2 promotes cell death through its serine protease activity and its ability to antagonize inhibitor of apoptosis proteins. $J$. Biol. Chem. 277no. 1, 445-454 (2002).

47. M. M. Hill, C. Adrain, P. J. Duriez, E. M. Creag, and S. J. Martin. Analysis of the composition, assembly kinetics and activity of native Apaf-1 apoptosomes. EMBO J. 23:2134-2145 (2004).

48. T. Z. Schafer, A. B. Parrish, K. M. Wright, S. S. Margolis, J. R. Marks, M. Deshmukh, and S. Kornbluth. Enhanced sensitivity to cytochrome $c$-induced apoptosis mediated by PHAPI in breast cancer cells. Cancer Res. 66no. 4, 2210-2218 (2006).

49. D. Chandra, S. B. Bratton, M. B. Person, Y. Tian, A. G. Martin, M. Ayres, H. O. Fearnhead, V. Gandhi, and D. G. Tang. Intracellular nucleotides act as critical prosurvival factors by binding to cytochrome $c$ and inhibiting apoptosome. Cell 125:1333-1346 (2006).

50. A. Samali, M. O'mahoney, J. Reeve, S. Logue, E. Szegezdi, J. McMahon, and H. O. Fearnhead. Identification of an inhibitor of caspase activation from heart extracts; ATP blocks apoptosome formation. Apoptosis 12no. 3, 465-474 (2007).

51. K. Cain, C. Langlais, X. M. Sun, D. G. Brown, and G. M. Cohen. Physiological concentrations of $\mathrm{K}^{+}$inhibit cytochrome $c$ dependent formation of the apoptosome. J. Biol. Chem. 276no. 45, 41985-41990 (2001).

52. Q. Bao, W. Lu, J. D. Rabinowitz, and Y. Shi. Calcium blocks formation of apoptosome by preventing nucleotide exchange in Apaf-1. Mol. Cell 25no. 2, 181-192 (2007).

53. T. J. DonnellMc and S. J. Korsmeyer. Progression from lymphoid hyperplasia to high-grade malignant lymphoma in mice transgenic for the $\mathrm{t}(14: 18)$. Nature 349:254-256 (1991).

54. S. H. Kaufmann and D. L. Vaux. Alterations in the apoptotic machinery and thier role in anticancer drug resistance. Oncogene 22no. 47, 7414-7430 (2003).

55. S. Zinkel, A. Gross, and E. Yang. Bcl-2 family in DNA damage and cell cycle control. Cell Death Differ. 13:1351-1359 (2006).

56. J. C. Reed. Proapoptotic multidomain Bcl-2/Bax family proteins: mechanisms, physiological roles, and therapeutic opportunities. Cell Death Differ. 13:1378-1386 (2006). 
57. R. Kim. Unknotting the roles of Bcl-2 and Bcl-XL in cell death Biochem. Biophys. Res. Commun. 333no. 2, 336-343 (2005).

58. J. L. Wang, D. Liu, Z. J. Zhang, S. Shan, X. Han, S. M. Srinisavula, C. M. Croce, E. S. Alnemri, and Z. Huang. Structure-based discovery of an organic compound that binds Bcl-2 protein and induces apoptosis of tumor cells. Proc. Natl. Acad. Sci. U. S. A. 97no. 13, 7124-7129 (2000).

59. S. P. Tzung, K. M. Kim, G. Basanez, C. D. Giedt, J. Simon, J. Zimmerberg, K. Y. Zhang, and D. M. Hockenbery. Antimycin A mimics a cell-death-inducing Bcl-2 homology domain 3. Nat. Cell Biol. 3:183-191 (2001).

60. T. Nakashima, M. Miura, and M. Hara. Tetrocarcin A inhibits mitochondrial functions of $\mathrm{Bcl}-2$ and suppresses its antiapoptotic activity. Cancer Res. 60:1229-1235 (2000).

61. S. L. Chan, M. C. Lee, K. O. Tan, L. K. Yang, A. S. Lee, H. Flotow, N. Y. Fu, M. S. Butler, D. D. Soejarto, A. D. Buss, and V. C. Yu. Identification of chelerythrine as an inhibitor of Bcl- $\mathrm{X}_{\mathrm{L}}$ function. J. Biol. Chem. 278:20453-20456 (2003).

62. M. F. Delftvan, A. H. Wei, K. D. Mason, C. J. Vandenberg, L. Chen, P. E. Czabotar, S. N. Willis, C. L. Scott, C. L. Day, S. Cory, J. M. Adams, A. W. Roberts, and D. C. S. Huang. The $\mathrm{BH} 3$ mimetic ABT-737 targets selective $\mathrm{Bcl}-2$ proteins and efficiently induces apoptosis via $\mathrm{Bak} / \mathrm{Bax}$ if $\mathrm{Mcl}-1$ is neutralized. Cancer Cell 10no. 5, 389-399 (2006).

63. G. Wang, Z. Nikolovska-Coleska, C. Y. Yang, R. Wang, G. Tang, J. Guo, S. Shangary, S. Qiu, W. Gao, D. Yang, J. Meagher, J. Stuckey, K. Krajewski, S. Jiang, P. P. Roller, H. O. Abaan, Y. Tomita, and S. Wang. Structure-based design of potent small-molecule inhibitors of anti-apoptotic Bcl-2 proteins. J. Med. Chem. 49no. 21, 6139-6142 (2006).

64. C. PoznakVan, A. D. Seidman, M. M. Reidenberg, M. M. Moasser, N. Sklarin, K. VanZee, P. Borgen, M. Gollub, D. Bacotti, T. J. Yao, R. Bloch, M. Ligueros, M. Sonenberg, L. Norton, and C. Hudis. Oral gossypol in the treatment of patients with refractory metastatic breast cancer: a phase I/ II clinical trial. Breast Cancer Res. Treat. 66no. 3, 239-248 (2001).

65. S. K. Tahir, X. Yang, M. G. Anderson, S. E. Morgan-Lappe, A. V. Sarthy, J. Chen, R. B. Warner, S. C. Ng, S. W. Fesik, S. W. Elmore, S. H. Rosenberg, and C. Tse. Influence of Bcl-2 family members on the cellular response of small-cell lung cancer cell lines to ABT-737. Cancer Res. 96no. 4, 600-608 (2007).

66. J. D. Lickliter, J. Cox, J. McCarron, N. R. Martinez, C. W. Schimdt, H. Lin, M. Nieda, and A. J. Nicol. Smallmolecule Bcl-2 inhibitors sensitise tumor cells to immunemediated destruction. Br. J. Cancer 96no. 4, 600-608 (2007).

67. S. Trudel, A. K. Stewart, Z. Li, Y. Shu, S. B. Liang, Y. Trieu, D. Reece, J. Paterson, D. Wang, and X. Y. Wen. The Bcl-2 family protein inhibitor, ABT-737, has substantial antimyeloma activity and shows synergistic effect with dexamethasone and melphalan. Clin. Cancer Res. 13no. 2Pt 1, 621-629 (2007).

68. Z. Zhang, L. Jin, X. Qian, M. Wei, Y. Wang, J. Wang, Y. Yang, $\mathrm{Q}$. Xu, and F. Liu. Novel Bcl-2 inhibitors: discovery and mechanism study of small organic apoptosis-inducing agents. Chembiochem 8no. 1, 113-121 (2007).

69. J. Qin, L. P. Xie, X. Y. Zheng, Y. B. Wang, Y. Bay, H. F. Shen, L. C. Li, and R. Dahiya. A component of green tea, (-)epigallocatechin-3-gallate, promotes apoptosis in T24 human bladder cancer cells via modulation of the PI3K/Akt pathway and $\mathrm{Bcl}-2$ family proteins. Biochem. Biophys. Res. Commun. 354no. 4, 852-857 (2007)

70. Y. D. Hsuuw and W. H. Chan. Epigallocatechin gallate dosedependently induces apoptosis or necrosis in human MCF-7 cells. Ann. N. Y. Acad. Sci. 1095:428-440 (2007).

71. T. Nishikawa, T. Nkajima, M. Moriguchi, S. Sekoguchi, M. Ishii, H. Takashima, T. Katagishi, H. Kimura, M. Minami, Y. Itoh, K. Kagawa, and T. Okanoue. A green tea polyphenol, epigallocatechin-3-gallate, induces apoptosis of human hepatocellular carcinoma, possibly through inhibition of $\mathrm{Bcl}-2$ family proteins. J. Hepatol. 44no. 6, 1074-1082 (2006).

72. B. F. Baker and B. P. Monia. Novel mechanisms for antisensemediated regulation of gene expression. Biochim. Biophys. Acta. 1489no. 1, 3-18 (1999).
73. R. Kim, M. Emi, K. Matsuura, and K. Tanabe. Antisense and nonantisense effects of antisense $\mathrm{Bcl}-2$ on multiple roles of Bcl2 as a chemosensitizer in cancer therapy. Cancer Gene Ther. 14:1-11 (2007).

74. Bedikian, M. Millward, H. Pehamberger, R. Conry, M. Gore U. Trefzer, A. Pavlick, R. DeConti, E. M. Hersh, P. Hersey, J. M. Kirkwood, and F. G. Haluska. Bcl-2 antisense (oblimersen sodium) plus dacarbazine in patients with advanced melanoma: the oblimersen melanoma study group. J. Clin. Oncol. 24:4738-4745 (2006).

75. S. O'Brien, J. O. Moore, T. E. Boyd, L. M. Larratt, A. Skotnicki, B. Koziner, A. A. Chanan-Khan, J. F. Seymour, R. G. Bociek, S. Pavletic, and K. R. Rai. Randomized Phase III trial of Flidarabine plus cyclophosphamide with or without oblimersen sobium (Bcl-2 antisense) in patients with relapsed or refractory chronic lymphocytic leukemia. J. Clin. Oncol. 25no. 9, 11141120 (2007).

76. W. Tan, Y. H. Loke, C. A. Stein, P. Millerr, and M. Colombini. Phosphorothioate oligonucleotides block the VDAC channel. Biophys. J. 2007 (in press; May 4).

77. W. Tan, J. C. Lai, P. Millerr, C. A. Stein, and M. Colombini. Phosphorothioate oligonucleotides reduce mitochondria membrane permeability to ADP. Am. J. Physiol. Cell. Physiol. 292no. 4, C1388-C1397 (2007).

78. R. S. Akhtar, J. M. Ness, and K. A. Roth. Bcl-2 family regulation of neuronal development and neurodegeneration. Biochim. Biophys. Acta. 1644:189-203 (2004).

79. N. Weisleder, G. E. Taffet, and Y. Capetanaki. Bcl-2 overexpression corrects mitochondrial defects and ameliorates inherited desmin null cardiomyopathy. Proc. Natl. Acad. Sci. U. S. A. 101:769-774 (2004).

80. M. Tanaka, S. Nakae, R. D. Terry, G. K. Mokhtari, F. Gunawan, L. B. Balsan, H. Kaneda, T. Kofidis, P. S. Tsao, and R. C. Robbins. Cardiomyocyte-specific Bcl-2 overexpression attenuates ischemia-reperfusion injury, immune response during acute rejection, and graft coronary artery disease. Blood 104:3789-3796 (2004).

81. Y. Han, A. Giroux, E. L. Grimm, R. Aspiotis, S. Francoeur C. I. Bayly, D. J. McKay, S. Roy, S. Xanthoudakis, and J. P. VaillancourtDiscovery of novel aspartyl ketone dipeptides as potent and selective caspase-3 inhibitors. Bioorg. Med. Chem. Lett. 14:805-808 (2004).

82. S. Toulmond, K. Tang, Y. Bureau, H. Ashdown, S. Degen, R. O'Donnell, J. Tam, Y. Han, J. Colucci, and A. GirouxNeuroproctective effects of M826, a reversible caspase-3 inhibitor, in the rat malonate model of Hutington's disease. $B r$. J. Pharmacol. 141:689-697 (2004).

83. S. Y. Kim, H. K. Oh, J. M. Ha, M. Y. Ahn, J. C. Shin, S. H. Baek, S. C. Lim, and Y. A. Joe. RGD-peptide presents anti-adhesive effect, but not direct proapoptotic effect on endothelial progenitor cells. Arch. Biochem. Biophys. 459no. 1, 40-49 (2007).

84. H. Jin, C. Xiao, G. Zhao, X. Du, Y. Yu, Y. Kang, and B. Wang. Induction of immature dendritic cell apoptosis by foot and mouth disease virus is an integrin receptor mediated event before viral infection. J. Cell. Biochem. 2007 (in press: Apr 11).

85. C. D. Buckley, D. Pilling, N. V. Henriquez, G. Parsonage, K. Threlfall, D. Scheel-Toellner, D. L. Simmons, A. N. Akbar, J. M. Lord, and M. Salmon. RGD peptides induce apoptosis by direct caspase-3 activation. Nature (Lond) 397:534-539 (1999).

86. H. Z. Zhang, S. Kasibhatla, Y. Wang, J. Herich, J. Guastella, B. Tseng, J. Drewe, and S. X. Cai. Discovery, characterization and SAR of gamboic acid as a potent apoptosis inducer by a HTS assay. Bioorg. Med. Chem. 12:309-317 (2004).

87. L. T. Jia, L. H. Zhang, C. J. Yu, J. H. Gui, M. Jin, Z. L. Ji, W. H. Wen, C. J. Wang, S. Y. Chen, and A. G. Yang. Specific tumoricidal activity of a secreted proapototic protein consisting of HER2 antibody and constitutively active caspase-3. Cancer Res. 63no. 12, 3257-3262 (2003).

88. S. F. Shariat, S. Desai, W. Song, T. Khan, J. Zhao, C. Nguyen, A. B. Foster, N. Greenberg, D. M. Spencer, and K. M. Slawin. Adenovirus-mediated transfer of inducible caspases: a novel "death switch" gene therapeutic approach to prostate cancer. Cancer Res. 61:2562-2571 (2001). 
89. E. C. LaCasse, G. G. Cherton-Horvat, K. E. Hewitt, L. J. Jerome, S. J Morris, E. R. Kandimalla, D. Yu, H. Wang, W. Wang, R. Zhang, S. Agrawal, J. Gillard, and J. P. Durkin. Preclinical characterization of AEG35156/GEM 640, a secondgeneration antisense oligonucleotide targeting X-linked inhibitor of apoptosis. Clin. Cancer Res. 12no. 17, 5231-5241 (2006).

90. R. Hedge, S. M. Srinisavula, Z. Zhang, R. Wassell, R. Mukattash, L. Cilenti, G. DuBois, Y. Lazebnik, A. S. Zervos, T. FernandesAlneol, and E. S. Alnemri. Identification of $\mathrm{Omi} / \mathrm{Htra} 2$ as a mitochondrial apoptotic serine protease that disrupts inhibitor of apoptotis protein-caspase interaction J. Biol. Chem. 277no. 1, 432-438 (2002).

91. L. Yang, T. Mashima, S. Sato, M. Mochizuki, H. Sakamoto, T. Yamori, T. Oh-Hara, and T. Tsuruo. Predominant suppresion of apoptosome by inhibitor of apoptosis protein in $\mathrm{H} 460$ cells: non-small cell lung cancer therapeutic effect of a novel polyarginine-conjugated Smac peptide. Cancer Res. 63no. 4, 831-837 (2003).

92. A. M. Verhagen, T. K. Kratina, C. J. Hawkins, J. Silke, P. G. Ekert, and D. L. Vaux. Identification of mammalian mitochondrial proteins that interact with IAPs via $\mathrm{N}$-terminal IAP binding motifs. Cell Death Differ. 14no. 2, 348-357 (2007).

93. Z. Nikolovska-Coleska, L. Xu, Z. Hu, Y. Tomita, P. Li, P. P. Roller, R. Wang, X. Fang, R. Guo, M. Zhang, M. E. Lippman, and D. Yu. Discovery of embelin as a cell-permeable, small-molecular weight Inhibitor of XIAP through structurebased computational screening of a traditional herbal medicine three-dimensional structure database. J. Med. Chem. 47no. 10, 2430-2440 (2004)

94. H. Sun, Z. Nikolovska-Colesca, C. Y. Yang, L. Xu, Y. Tomita, K. Krajevski, P. P. Roller, and S. Wang. Structure-based design, synthesis and evaluation of conformationally constrained mimetics of the second mitochondria-derived activator of caspase that target the X-linked inhibitor of apoptosis protein/caspase-9 interaction site. J. Med. Chem. 47:4147-4150 (2004).

95. G. J. Mizejewski and G. Butterstein. Survey of functional activities of alpha-fetoprotein derived growth inhibitory peptides: review and prospects. Curr. Protein Pept. Sci. 7no. 1, 73100 (2006).

96. E. Dudich and L. Semenkova. $\alpha$-Fetoprotein causes apoptosis in tumor cells via a pathway independent of CD95, TNFR1 and TNFR2 through activation of caspase-3-like proteases. Eur. J. Biochem. 266no. 3, 750-761 (1999).

97. L. Semenkova, E. Dudich, I. Dudich, N. Tokhtamisheva, E. Tatulov, Y. Okruzhnov, J. Garcia-Foncillas, J. A. Palo-Cubillo, and T. Korpela. Alpha-fetoprotein positively regulates cytochrome $c$-mediated caspase activation and apoptosome complex formation. Eur. J. Biochem. 270no. 21, 4388-4399 (2003).

98. E. Dudich, L. Semenkova, I. Dudich, A. Denesyuk, E. Tatulov, and T. Korpela. Alpha-fetoprotein antagonized X-linked inhibitor apoptosis protein anticaspase activity and disrupts XIAPcaspase interaction. FEBS J. 273no. 16, 3837-3849 (2006).

99. D. C. Altieri. Survivin versatile modulation of cell division and apoptosis in cancer. Oncogene 22no. 53, 8581-8589 (2003).

100. B. Spaulding, D. Pan, A. Ghadersohi, G. Nielsen, S. Jensen, F. Gellert, X. Ling, M. Zhang, A. Black, and F. Li. Characterization of the $12 \mathrm{C} 4$ survivin monoclonal antibody and insight into the expression of survivin in human adult tissues. Histopatology 49no. 6, 622-633 (2006).

101. T. Takatani, K. Takahashi, Y. Uozumi, E. Shikata, Y. Yammamoto, T. Ito, T. Matsuda, S. W. Schaffer, Y. Fujio, and J. Azuma. Taurine inhibits apoptosis by preventing formation of the Apaf1/caspase-9 apoptosome. Am. J. Physiol., Cell Physiol. 287no. 4, C949-C953 (2004).

102. G. Malet, A. G. Martin, M. Orzaez, M. J. Vicent, I. Masip, G. Sanclimens, A. Ferrer-Montiel, I. Mingarro, A. Messeguer, H. O. Fearnhead, and E. Perez-Paya. Small molecule inhibitors of Apaf-1-related caspase-3/-9 activation that control mitochondrial-dependent apoptosis. Cell Death Differ. 13no. 9, 1523-1532 (2006).

103. Y. Furukawa, K. Sutheesophon, T. Wada, M. Nishimura, Y. Saito, H. Ishii, and Y. Furukawa. Methylation silencing of the Apaf-1 gene in acute leukemia. Mol. Cancer Res. 3no. 6, 325334 (2005)

104. F. Christoph, S. Wekert, C. Kempkensteffen, H. Krause, M. Schostak, K. Miller, and M. Schrader. Regularly methylated novel pro-apoptotic genes associated with recurrence in transitional cell carcinoma of the bladder. Int. J. Can. 119:1396-1402 (2006).

105. H. Yamamoto, J. Gil, S. Schwartz Jr., and M. Perucho. Frameshift mutations in Fas, Apaf-1, and Bcl-10 in gastrointestinal cancer of the microsatellite mutator phenotype. Cell Death Differ. 7:238-239 (2000).

106. T. Watanabe, Y. Hirota, Y. Arakawa, Y. Fujisawa, H. Tachibana, M. Hasegawa, J. Yamashita, and Y. Hayashi. Frequent LOH at chromosome 12q22-23 and Apaf-1 inactivation in glioblastoma. Brain Pathol. 13:431-439 (2003).

107. S. Bala, H. Oliver, B. Renault, K. Montgomery, S. Dutta, P. Rao, J. Houldsworth, R. Kuperlapati, X. Wang, R. S. Chaganti, and V. V. Murty. Genetic analysis of the Apaf1 gene in male germ cell tumors. Genes Chromosomes Cancer 28:258-268 (2000)

108. M. S. Soengas, P. Capodieci, D. Polsky, J. Mora, M. Esteller, X. Opitez-Araya, R. McCombie, J. G. Herman, W. L. Gerald, Y. A. Labenik, Cordon-Cardo', and S. W. Lowe. Inactivation of the apotosis effector Apaf-1 in malignant melanoma. Nature 409:207-211 (2001).

109. L. T. C. Peltenburg, E. C. deBruin, D. Meersma, N. P. M. Smith, P. I. Schrier, and J. P. Medema. Expression and function of the apoptosis effector Apaf1 in melanoma. Cell Death Differ. 12:678679 (2005).

110. M. S. Soengas, W. L. Gerald, C. Cordon-Cardo, Y. Lazebnik, and S. W. Lowe. Apaf1 expression in malignant melanoma. Cell Death Differ. 13:352-353 (2006).

111. S. Wang, Y. Yan-Neale, R. Cai, I. Alimov, and D. Cohen. Activation of mitochondrial pathway is crucial for tumor selective induction of apoptosis by LAQ824. Cell Cycle 5no. 15, 1662-1668 (2006)

112. P. A. Svingen, D. Loegering, J. Rodriquez, X. W. Meng, P. W. Mesner, J. S. Holbeck, A. Monks, S. Krajewski, D. A. Scudiero, E. A. Sausville, J. C. Reed, Y. A. Lazebnik, and S. H. Kaufmann. Components of cell death machine and drug sensitivity of the National Cancer institute cell line panel. Clin. Cancer Res. 10:6807-6820 (2004).

113. B. Besse, C. Cande, J. P. Spano, A. Martin, D. Khayat, T. ChevalierLe, T. Tursz, L. Sabatier, J. C. Soria, and G. Kroemer. Nuclear localization of Apaf-1 predicts long term survival in operable lung cancer. Clin. Cancer Res. 10no. 17, 5665-5669 (2004).

114. E. Ferrando-May, V. Cordes, I. Biller-Ckovric, J. Mirkovic, D. Gorlich, and P. Nicotera. Caspases mediate nucleoporin cleavage, but not early redistribution of nuclear transport factors and modulation of nuclear permeability in apoptosis. Cell Death Differ. 8:495-505 (2001). 